\title{
Free-Standing S-CNT-rGO Nanocomposite Paper Cathodes for Li-S Batteries
}

\author{
Büşra Şahin ${ }^{1}$, Hilal Köse ${ }^{2,3}$, Şeyma Dombaycığlü ${ }^{2,3}$, Ali Osman Aydın,3 \\ ${ }^{1}$ Sakarya University \\ Institute of Natural Sciences, Sakarya, Turkey \\ busra.sahin.9342@gmail.com \\ ${ }^{2}$ Sakarya University \\ Department of Chemistry, Arts\&Sciences Faculty, Sakarya, Turkey \\ ${ }^{3}$ Sakarya University Research, Development and Application Center (SARGEM) \\ Esentepe Campus, Sakarya, Turkey \\ hkose@sakarya.edu.tr; sdombaycioglu@sakarya.edu.tr; aaydin@sakarya.edu.tr
}

\section{Extended Abstract}

For electric vehicles (EVs), hybrid electric vehicles (HEVs), and smart electric grids, it is important to develop advanced energy storage systems due to the ever-increasing demands for high energy density and long-life energy sources. With a high theoretical gravimetric energy density of $2500 \mathrm{Wh} \mathrm{kg}^{-1}$, Lithium-sulfur (Li-S) batteries are considered to be one of the most promising candidates in this respect [1]. However, the practical electrochemical performance of Li-S battery have been restricted by the low conductivity of sulfur and the insoluble and insulating lithium sulfides, $\mathrm{Li}_{2} \mathrm{~S}_{2} / \mathrm{Li}_{2} \mathrm{~S}$ on the cathode surface [2]. To resolve these problems, especially carbon materials are used to increase the conductivity. Due to their high electrical conductivity, porous carbon, carbon nanotubes $(\mathrm{CNTs})$ and reduced graphene oxide ( $\mathrm{rGO}$ ) are generally used to enhance the conductivity of sulfur and $\mathrm{Li}_{2} \mathrm{~S} / \mathrm{Li}_{2} \mathrm{~S}_{2}$ during charge-discharge process [3].

In this work, we produced S-CNT-rGO nanocomposites as binderless free-standing paper. Firstly, functionalized MWCNTs were prepared with $\mathrm{H}_{2} \mathrm{SO}_{4} / \mathrm{HNO}_{3}$ mixture $(3: 1, \mathrm{v} / \mathrm{v})$ and graphite oxide was produced by modified Hummers method. Then, $\mathrm{Na}_{2} \mathrm{~S}_{2} \mathrm{O}_{3} .5 \mathrm{H}_{2} \mathrm{O}$ precursor was added into the mixture of graphite oxide and CNTs. After ultrasonication of $2 \mathrm{~h}$, $\mathrm{HCl}$ solution was added dropwise to resulting homogeneous suspension. During this process, the sulfur anions reduced and deposited on the surface of the graphene oxide and CNTs as sulfur nanoparticles. The resulting suspension was filtered through a $0.22 \mu \mathrm{m}$ porous PVDF membrane filter (Millipore, Durapore Membrane) with a vacuum filtration system and washed three times with deionized water and ethanol. After the paper dried, it was peeled off the membrane and flexible SCNT-GO paper was obtained. To obtain S-CNT-rGO from this structure, the S-CNT-GO paper was treated with a dilute solution of hydrazine as reducing agent. Obtained papers were characterized by field emission scanning electron microscopy (FESEM), energy dispersive X-ray spectrometer (EDS), X-ray diffraction (XRD) and Fourier transform infrared spectroscopy (FT-IR) analyses. Electrochemical analysis was performed using battery tester device. Charge-discharge capabilities, specific capacity and capacity retention parameters were investigated of the cathode electrodes assembled in the type of CR2032 cells. When the results have been evaluated, it has seen that the aimed structure of S-CNT-rGO has been obtained for advanced Li battery applications.

\section{Acknowledgments}

This work is supported by the Scientific and Technological Research Council of Turkey (TÜBİTAK) under the contract number 118M265. The authors thank the TÜBİTAK-MAG workers for their financial support.

\section{References}

[1] J. Liu, Q. Zhang, Y-K. Sun, "Recent progress of advanced binders for Li-S batteries," J. Power Sour., vol. 396, pp. 19-32, 2018. 
[2] Y-Y. Hsieh, L. Zhang, D. DeArmond, S.N. Kanakaraj, P.K. Adusei, N.T. Alvarez, Y. Fang, J. Daum, V. Shanov, "Integrated graphene-sulfur cathode and separator with plasma enhancement for Li-S batteries," Carbon, vol. 139, pp. 1093-1103, 2018.

[3] Q. Liu, Q. Jiang, L. Jiang, J. Peng, Y. Gao, Z. Duan, X. Lu, "Preparation of $\mathrm{SnO}_{2} @ \mathrm{rGO} / \mathrm{CNTs} / \mathrm{S}$ composite and application for lithium-sulfur battery cathode material," Appl. Surf. Sci., vol. 462, pp. 393-398, 2018. 